\title{
Estudo do Uso de Resíduo da Fresagem de Pavimentos Flexíveis em Concretos Estruturais
}

\author{
COSTA, Vitória Silveira da ${ }^{1}$ \\ TEIXEIRA, Fernando Ritiéle ${ }^{2}$ \\ RODRIGUES, Jean Morais ${ }^{3}$ \\ TORRES, Ariela da Silva ${ }^{4}$
}

\begin{abstract}
1PROGRAU, Universidade Federal de Pelotas, Pelotas, Brasil. vitoriascosta@yahoo.com.br 2PROGRAU, Universidade Federal de Pelotas, Pelotas, Brasil. fernandoteixeira5400@gmail.com ${ }^{3}$ ECOSUL, Empresa Concessionária de Rodovias do Sul S.A, Pelotas, Brasil. jean.rodrigues@ecosul.com.br 4PROGRAU, Universidade Federal de Pelotas, Pelotas, Brasil. arielatorres@gmail.com
\end{abstract}

\section{Resumo}

Os agregados graúdos ocupam de $48 \%$ a $53 \%$ do volume total do concreto, sendo a extração e britagem do agregado grande responsável por consumir recursos naturais não renováveis. Este trabalho avaliou a influência da substituição parcial do agregado graúdo natural pelo agregado graúdo reciclado proveniente da fresagem de pavimentos flexíveis de concreto também conhecido como RAP (Reclaimed Asphalt Pavement). A avaliação foi feita a partir de testes de resistência à compressão em concreto, além do comportamento físico, a partir da absorção por sução capilar e por imersão. Para realização do estudo, foi fixado um traço de concreto, com resistência de $25 \mathrm{MPa}$, e utilizou-se as porcentagens de 0 , $20 \%$ e $30 \%$ de substituição. Como resultados, constatou-se uma queda no desempenho mecânico dos concretos confeccionados com RAP em relação ao concreto de referência. Em relação a absorção por capilaridade os traços com substituições apresentaram uma queda acentuada na absorção capilar em relação ao traço de referência. Na absorção por imersão os concretos com substituições apresentaram um ligeiro aumento na taxa de absorção comparado com o traço de referência. Entretanto, apesar da queda na resistência a compressão conseguiu-se confeccionar uma mistura com características de um concreto estrutural, de acordo com a NBR 6118/2014.

Palavras-Chave: Resíduo da fresagem de pavimentos flexíveis; Agregado graúdo; Concreto; Sustentabilidade; Tecnologia da Arquitetura.

\begin{abstract}
The large aggregates occupy $48 \%$ to $53 \%$ of the total volume of the concrete, being an extraction and aggregation of the large owner responsible for consuming nonrenewable natural resources. This work had a natural aggregation advantage by the recycled aggregate coming from the milling of flexible concrete pavements and known as RAP (Reclaimed Asphalt Pavement). The evaluation was made from tests of resistance to anesthesia under study, in addition to physical compliance, from absorption by capillary suppression and by immersion. For the study, a concrete trait was fixed, with a resistance of 25 $\mathrm{MPa}$, and used as $0,20 \%$ and $30 \%$ replacement images. As it behaves, there is no improvement in the performance of the concrete made with RAP in relation to the reference concrete. In relation to a capillarity limitation in relation to the reference traffic. The absorption by immersion in concretes with the substitutions is an increase in the absorption rates with the reference trace. However, despite the fall in strength, a mixture with structural characteristics was achieved according to NBR 6118/2014.
\end{abstract}

Key-Words: Residue of the milling of flexible floors; Aggregate; Concrete; Sustainability; Architecture Technology. 


\section{Introdução}

Pode-se dizer que no campo da sustentabilidade existem fatores que devem ser considerados a fim de resolver os problemas advindos com a produção de resíduos, sendo os aspectos econômicos, sociais e ambientais os mais significativos. Atualmente, projetar edificações sustentáveis, além da correta especificação de materiais e subsistemas construtivos, é um desafio sem precedentes na indústria da construção civil.

A reciclagem de resíduos apresenta várias vantagens em relação à utilização de recursos naturais, destaca-se a redução do volume de extração de matérias-primas, redução do consumo de energia e menores emissões de poluentes. Em vista disso é de extrema importância progredir nas técnicas de reaproveitamento de materiais alternativos, como forma de atenuar os impactos ambientais.

O concreto atualmente é o material de construção mais popular no mundo devido ao seu custo relativamente barato e a sua versatilidade. O concreto é adaptável a uma ampla variedade de campos da engenharia civil, portanto, o papel do concreto na promoção do desenvolvimento da sociedade continuará, sem dúvida, a desempenhar um papel crucial no futuro. No entanto, deve-se salientar que a indústria de concreto consome enormes quantidades de agregados naturais que causam a destruição do meio ambiente. Portanto, há uma necessidade urgente encontrar e fornecer substitutos adequados para o agregado natural (ERDEM e BLANKSON 2014).

Pesquisas têm se mostrado bastante promissoras, quanto à incorporação de resíduos do setor industrial em concretos, como forma de reduzir o consumo de matérias-primas não renováveis e até mesmo melhorar as propriedades do concreto.

A reciclagem é o conjunto de técnicas que tem por finalidade o aproveitamento de resíduos e detritos, a fim de reintroduzi-los no ciclo de produção (MENEZES et al.,2002; BEZERRA, 2010). Atualmente, a maioria dos materiais reciclados utilizados para produção de concreto é empregada na substituição dos agregados graúdos - como é o caso do resíduo de construção e demolição (RCD) utilizado no trabalho desenvolvido por Silva et al. (2015). Pode-se destacar alguns trabalhos em que a substituição é realizada nos agregados miúdos, como o vidro cominuído empregado no trabalho de Atoyebi e Sadiq (2018), e até mesmo substituição do cimento por escórias de alto forno granulada e cinzas volantes no estudo de Karein et al. (2017).

Em vista disso, a utilização de resíduos possui grande potencial para produzir novos materiais com melhor desempenho mecânicos e mais duráveis. Consequentemente devido à expansão da malha rodoviária, um resíduo que veem crescendo em grande quantidade é proveniente da fresagem de pavimentos asfálticos também conhecido como RAP (Reclaimed Asphalt Pavement).

Tendo em vista que o principal método de manutenção das rodovias é a fresagem das camadas danificadas de pavimento e posterior recapeamento asfáltico, tal material é abundante, isso se deve principalmente ao aumento populacional, a melhoria das condições de vida, a aumento no número de veículos automotivos produzidos. Nos últimos anos, a reciclagem de RAP tem crescido para resolver o problema do armazenamento de resíduos e para limitar o uso de recursos naturais (BOUSSETTA, 2018).

De acordo com Erdem e Blankson (2014), o concreto é material de construção mais popular no mundo devido ao seu custo relativamente baixo e a versatilidade de uso. O concreto é adaptável a uma ampla variedade de uso: desde edifícios a pavimentos rodoviários. Portanto, urge a necessidade de encontrar alternativas que busquem substituir os agregados naturais por agregados reciclados.

Em paralelo ao desenvolvimento tecnológico do concreto e o expressivo crescimento da produção, a incorporação de resíduos no concreto, surge como uma alternativa mitigatória para a redução dos impactos ambientais causadas pela extração de matérias prima não renováveis utilizadas na produção do concreto. No Brasil, em função da vida útil de projeto para pavimentos flexíveis ser de 10 anos, 
considerando a malha viária brasileira pavimentada ser de $210.618,8 \mathrm{~km}$, a largura média das pistas de $7,0 \mathrm{~m}$ e a espessura de fresagem ser de $6 \mathrm{~cm}$, estima-se um volume total de $88.459,896 \mathrm{~m}^{3}$ de fresado asfáltico gerado a cada 10 anos. (CNT,2017).

A partir de todas estas justificativas, o presente estudo teve como objetivo avaliar o comportamento físico-mecânico de concretos estruturais produzidos com RAP, em substituição ao agregado graúdo natural.

\section{Revisão Bibliográfica}

De acordo com Neville (2015), aproximadamente $75 \%$ do volume de concreto são ocupados pelos agregados, dessa forma a qualidade do agregado é de extrema importância. Os agregados não contribuem somente na resistência do concreto, também afetam significativamente as propriedades do material, como a durabilidade e o desempenho estrutural do concreto.

Os agregados desempenham um papel importante na qualidade dos concretos, seja no estado fresco ou endurecido. No estado fresco os agregados podem influenciar na trabalhabilidade e no teor de argamassa do concreto, já no estado endurecido exerce influência sobre a estabilidade dimensional, durabilidade e no módulo de elasticidade do concreto.

No que tange aos problemas ambientais oriundos do processo de extração dos agregados, a principal consequência da extração está relacionada ao assoreamento de rios e alteração do curso d'água, desmatamento e desertificação do relevo, além do esgotamento de jazidas naturais e a emissão de $\mathrm{CO}_{2}$ durante o processo de extração.

Nesse contexto, buscando reduzir o impacto ambiental decorrente da extração dos agregados, alguns estudos utilizaram o resíduo da fresagem de pavimentos flexíveis (RAP) para produção do concreto, e observaram que apesar dos concretos produzidos com substituição parcial do agregado natural pelo RAP provocar uma queda na resistência à compressão, ainda assim é possível seu emprego como concreto estrutural. As porcentagens de substituição mais utilizadas em estudos que substituíram parte do agregado graúdo natural pelo RAP variam entre $20 \%$ e $100 \%$.

Al-Mufti e Fried (2017), investigaram o efeito da substituição do agregado graúdo natural pelo RAP na produção de concretos, os autores concluíram que a substituição de $25 \%$ reduziu a resistência à compressão em $27 \%$ na idade de 28 dias. Este estudo também estabelece o uso de técnicas não destrutivas - ultrassonografia e esclerometria na avaliação de concreto contendo diferentes porcentagens de RAP durante as idades iniciais do concreto. Como resultados para os ensaios não destrutivos, os teores de substituição afetaram os resultados de forma negativa.

Erdem e Blankson (2014), investigaram a substituição de 100\% do agregado graúdo natural pelo RAP na produção de concretos. Os resultados demostraram que a presença de concreto reciclado agregado no concreto pode levar a um aumento do concreto resistência à flexão que pode ser benéfica para algumas áreas da construção.

Face o exposto, o RAP é um material que apresenta potencial para ser utilizado em substituição parcial ao agregado graúdo na produção de concretos estruturais, uma vez que os resultados obtidos em estudos analisados apresentaram valores satisfatórios em relação a NBR 6118, a qual apresenta o valor de 20 Mpa para concretos estruturais.

\section{Materiais e Métodos}

Para a realização do experimento, este estudo foi dividido em: coleta do resíduo da fresagem de pavimentos flexíveis (RAP), preparação dos agregados reciclados (RAP), ensaio de empacotamento dos agregados naturais e reciclados, caracterização dos agregados naturais e reciclados, dosagem e moldagem de corpos de prova para testes, realização de ensaios em laboratório nos corpos de prova e 
posterior tratamento dos dados.

\subsection{Coleta e Caracterização dos Agregados Naturais e Reciclados}

Como etapa inicial do trabalho, teve-se a coleta dos agregados reciclados - obtidos junto a Empresa Concessionária de Rodovias do Sul S.A (ECOSUL) no município de Pelotas. O resíduo (Figura 1) foi transportado até o laboratório da Engenharia Civil da UFPel onde foi disposto para peneiramento e caracterização. Na etapa de peneiramento do RAP, utilizou-se apenas os agregados passantes na peneira $12,5 \mathrm{~mm}$ e os retidos na peneira $4,8 \mathrm{~mm}$, em função de que este intervalo granulométrico ao qual caracteriza a brita 0 .

Figura 1: Resíduo proveniente da fresagem de pavimentos asfálticos.

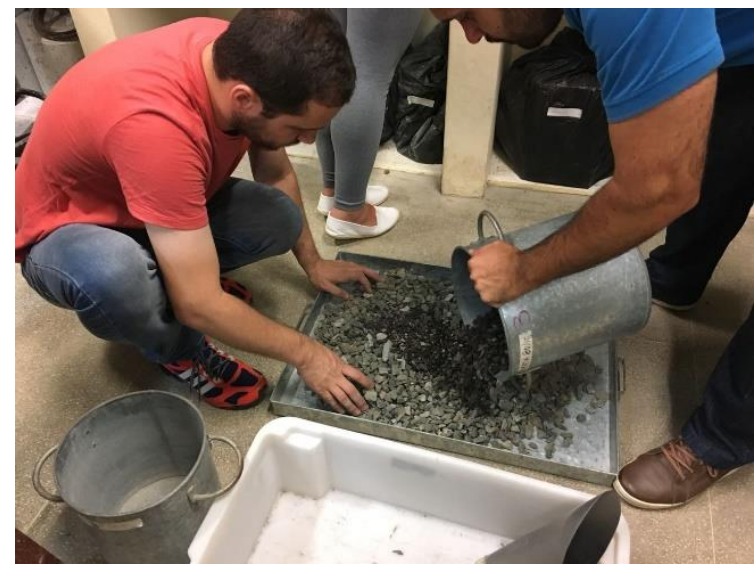

Utilizou-se o método experimental proposto por O'Reilly (1992), através do ensaio de empacotamento dos agregados graúdos, foi determinado que a composição de $20 \%$ do agregado reciclado com $80 \%$ do agregado natural, e $30 \%$ do agregado reciclado com $70 \%$ do agregado graúdo natural, apresenta uma maior compacidade do esqueleto granular.

Como fase final desta etapa, tem-se os ensaios de caracterização física dos agregados. Os materiais utilizados no trabalho foram, como agregado graúdo utilizou-se a brita 1, para agregado miúdo a areia média e como agregado reciclado o RAP, as características destes materiais estão dispostas na Tabela 1.

Tabela 1: Caracterização dos agregados

\begin{tabular}{|c|c|c|c|}
\hline Tipo de ensaio & $\begin{array}{l}\text { Agregado } \\
\text { miúdo }\end{array}$ & $\begin{array}{l}\text { Agregado } \\
\text { graúdo }\end{array}$ & $\begin{array}{c}\text { Agregado } \\
\text { reciclado } \\
\text { (RAP) } \\
\end{array}$ \\
\hline \multirow{2}{*}{$\begin{array}{c}\text { Composição } \\
\text { granulométrica/ } \\
\text { NBR NM } \\
\text { 248:2003 }\end{array}$} & $\begin{array}{c}\emptyset \text { máx } \\
(\mathrm{mm})\end{array}$ & 19,00 & 9,50 \\
\hline & $\begin{array}{c}\text { Módulo de } \\
\text { Finura }\end{array}$ & 4,69 & 6,26 \\
\hline $\begin{array}{c}\text { Massa específica } \\
\left(\mathrm{g} / \mathrm{cm}^{3}\right) / \mathrm{NBR} \\
\text { NM 52:2009 }\end{array}$ & 2,62 & 2,60 & 2,40 \\
\hline $\begin{array}{c}\text { Massa unitária } \\
\text { solta }\left(\mathrm{g} / \mathrm{cm}^{3}\right) \\
\text { /NBR NM } \\
45: 2009 \\
\end{array}$ & 1,55 & 1,41 & 1,31 \\
\hline $\begin{array}{c}\text { Índice de } \\
\text { volume de } \\
\text { vazios (\%)/ NBR } \\
\text { NM 45:2009 }\end{array}$ & 40,87 & 43,54 & 38,50 \\
\hline
\end{tabular}




\begin{tabular}{clll}
$\begin{array}{c}\text { Absorção (\%)/ } \\
\text { NBR NM }\end{array}$ & 3,67 & 1,54 & 1,48 \\
53:2003 e NBR & & \\
NM 30:2001 & & \\
\hline \multicolumn{3}{c}{ Fonte: Autores }
\end{tabular}

\subsection{Dosagem e Moldagem de Corpos de Prova}

Com relação a dosagem concreto, foi utilizado o método da $A B C P / A C l$ e resistência característica à compressão (fck) de $25 \mathrm{Mpa}$, sendo o valor de resistência exigido adotado segundo a NBR 6118 a qual estabelece valores para tipos de ambiente e classes de agressividades. A partir deste procedimento determinou-se o traço unitário do concreto referência e os traços utilizados com o RAP, conforme Tabela 2.

Tabela 2: Dosagem concreto

\begin{tabular}{ccccc}
\hline $\begin{array}{c}\text { Teor de } \\
\text { subst. }\end{array}$ & $\begin{array}{c}\text { Traço } \\
\text { (cimento: } \\
\text { areia: } \\
\text { brita:RAP) }\end{array}$ & $\begin{array}{c}\text { Relação } \\
\text { a/c }\end{array}$ & RAP & Slump \\
\hline Ref. & $\begin{array}{c}1: 2,42: 2,58: \\
0\end{array}$ & 0,60 & $0 \%$ & $100 \mathrm{~mm}$ \\
\hline $20 \%$ & $\begin{array}{c}1: 2,42: 2,06: \\
0,52\end{array}$ & 0,60 & $20 \%$ & $90 \mathrm{~mm}$ \\
\hline $30 \%$ & $\begin{array}{c}1: 2,42: 1,81: \\
0,77\end{array}$ & 0,60 & $30 \%$ & $80 \mathrm{~mm}$ \\
\hline \multicolumn{5}{c}{ Fonte: Autores } \\
\end{tabular}

A mistura dos concretos foi feita em betoneira intermitente de eixo inclinado NBR 5738 (ABNT, 2008). Foram moldados corpos de prova cilíndricos $(10 \times 20 \mathrm{~cm})$. O cimento utilizado foi o Cimento Portland de Alta Resistencia Inicial (CPV-ARI). O cimento foi escolhido por conter menor teor de adições ativas entre os disponíveis, o que facilita o entendimento da ação do RAP no concreto.

Após a moldagem, os corpos-de-prova foram curados submersos em tanque de água saturado com cal, durante 7 dias, de acordo com as especificações da NBR 5738 (ABNT, 2008).

\subsection{Realização de ensaios em laboratório}

Para facilitar o entendimento do programa experimental, na Tabela 3 são detalhadas todas as propriedades estudadas neste trabalho, bem como a quantidade de amostras - corpos de prova (cp) e as normas utilizadas nos procedimentos.

Tabela 3: Metodologia dos ensaios realizados

\begin{tabular}{cccc}
\hline \multirow{4}{*}{ Ensaio } & Detalhes & Norma \\
\hline \multirow{3}{*}{ Mecânicos } & Resistência à & 5 cp por & NBR \\
& traço: 7 & 5739 \\
& compressão & dias & $(2007)$ \\
\hline \multirow{4}{*}{ Físicos } & Absorção de & 3 cp por & NBR \\
& água por & traço: 7 & 9778 \\
& imersão & dias & $(2009)$ \\
\cline { 2 - 4 } & Absorção de & 3 cp por & NBR \\
& água por & traço: 7 & 9779 \\
& capilaridade & dias & $(2009)$ \\
\hline \multicolumn{4}{c}{ Fonte: Autores } \\
\end{tabular}




\subsection{Tratamento estatístico dos dados}

A análise estatística dos dados foi realizada utilizando o teste de análise de variância (ANOVA), que testa a variação entre grupos tomando como referência a variação dentro destes. A hipótese de nulidade é a de que as médias são todas iguais. Por meio do teste $F$ (distribuição de Fischer) é possível observar a significância estatística da variabilidade das médias entre os grupos. O valor "p-value" (probabilidade - distribuição t de student) menor que 0,05 designa que a relação entre as variáveis é estatisticamente significativa a um nível de confiança de $95 \%$.

\section{Resultados e Discussões}

\subsection{Resistência à Compressão Axial}

A Figura 2 mostra os resultados da resistência à compressão, utilizando $0 \%, 20 \%$, e $30 \%$ de agregado graúdo reciclado da fresagem de pavimentos flexíveis (RAP) em substituição ao agregado graúdo natural. Sendo a análise estatística de desvio padrão e coeficiente de variação apresentado na Tabela 4.

Figura 2: Resistência à compressão aos 7 dias de idade

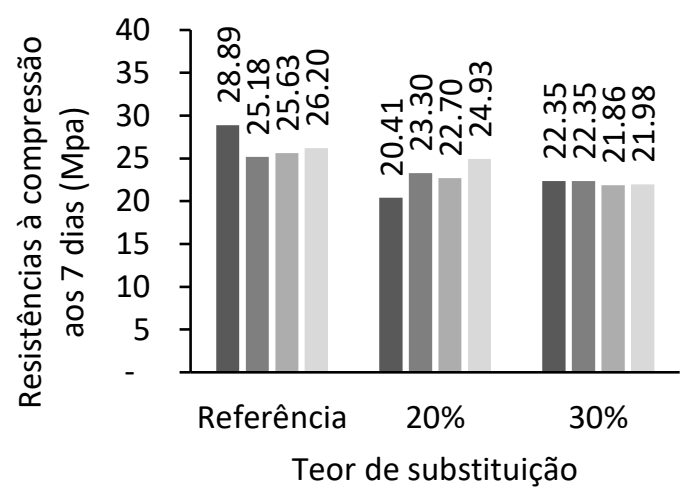

Fonte: Autores

Tabela 4: Dosagem concreto

\begin{tabular}{ccc}
\hline $\begin{array}{c}\text { Teor de } \\
\text { substituição }\end{array}$ & $\begin{array}{c}\text { Desvio } \\
\text { padrão }\end{array}$ & $\begin{array}{c}\text { Coeficiente de } \\
\text { variação }\end{array}$ \\
\hline Ref. & $1,66 \%$ & $6,27 \%$ \\
$20 \%$ & $1,87 \%$ & $8,18 \%$ \\
$30 \%$ & $0,25 \%$ & $1,13 \%$ \\
\hline
\end{tabular}

Fonte: Autores

Verifica-se que a substituição do agregado graúdo natural pelo agregado reciclado resultou em uma diminuição na resistência à compressão axial, esse comportamento pode ser explicado devido à presença de filme asfáltico em torno dos agregados, o que torna os agregados lisos e propicia a falha na aderência da matriz cimentícia com o agregado reciclado, de acordo com Sachet (2013).

A Figura 3 apresenta os resultados obtidos para resistência de compressão axial aos 7 dias de idade. 
Figura 3: Resistência à compressão axial aos 7 dias

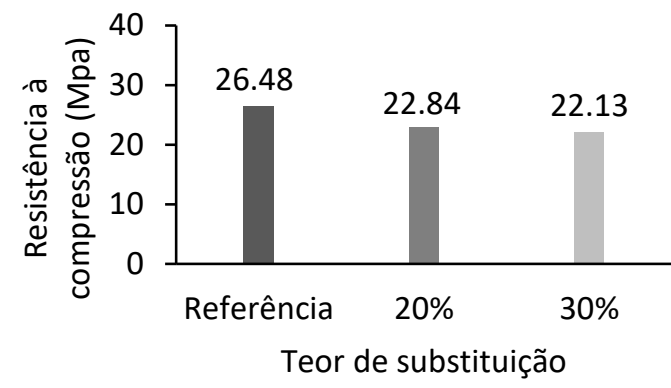

Fonte: Autores

Avaliando os dados, nota-se que, a resistência à compressão uniaxial para os teores de substituição $20 \%$ e $30 \%$ do agregado graúdo natural pelo RAP, obtiveram respectivamente um decréscimo de $15,94 \%$ e $19,63 \%$, se comparados ao traço de referência, embora tenha havido decréscimo na resistência à compressão uniaxial nas amostras com substituição, elas continuam tendo uma boa resistência à compressão quando comparadas a amostra de referência, apresentando resistência que permite seu emprego como concreto estrutural de acordo com NBR 6118 (ABNT, 2014). Os resultados encontrados corroboram os estudos de Sachet (2013), Erdem e Blankson (2014) e Al-Mufti e Fried (2017).

\subsection{Absorção por Capilaridade}

A partir da Tabela 5, é possível concluir que ao final do ensaio de absorção de água (72 horas), as amostras com $20 \%$ de teor de substituição tiveram um decréscimo de $55,55 \%$ na taxa de absorção em relação ao concreto de referência. Já as amostras produzidas com $30 \%$ de agregados reciclados tiveram um decréscimo de $47,36 \%$ na taxa de absorção.

Tabela 5: Resultados do ensaio de absorção por capilaridade

\begin{tabular}{|c|c|c|c|c|}
\hline \multirow{2}{*}{$\begin{array}{c}\text { Teor } \\
\text { de } \\
\text { subst. }\end{array}$} & \multicolumn{2}{|c|}{$\begin{array}{l}\text { Absorção por } \\
\text { capilaridade } \\
\left(\mathrm{g} / \mathrm{cm}^{2}\right)\end{array}$} & \multirow{2}{*}{$\begin{array}{c}\text { Altura } \\
\text { capilar } \\
\text { média } \\
\text { (cm) }\end{array}$} & \multirow{2}{*}{$\begin{array}{c}\text { Raio do } \\
\text { capilar } \\
\text { médio } \\
\text { (cm) }\end{array}$} \\
\hline & $\begin{array}{l}\text { Desvio } \\
\text { padrão }\end{array}$ & $\begin{array}{c}\text { Coef. de } \\
\text { variação }\end{array}$ & & \\
\hline Ref. & 0,08 & 7,21 & 9,50 & $2,41 \mathrm{E}-06$ \\
\hline $20 \%$ & 0,02 & 2,63 & 8,50 & 1,93E-06 \\
\hline $30 \%$ & 0,07 & 9,72 & 8,17 & $1,78 \mathrm{E}-06$ \\
\hline
\end{tabular}

Ficou constatado que na absorção de água por capilaridade, diferente do ensaio de resistência à compressão, o teor de substituição influenciou de forma positiva os resultados, pois quanto maior for o teor de RAP no concreto, menor é a tendência à absorção de água, menor altura de ascensão capilar e menor raio do capilar médio.

A Figura 4 apresenta os resultados obtidos no ensaio de absorção capilar aos 7 dias $s$ dados, nota-se que, a resistência à compressão uniaxial para os teores de substituição. 
Figura 4: Resultados ensaio absorção por capilaridade

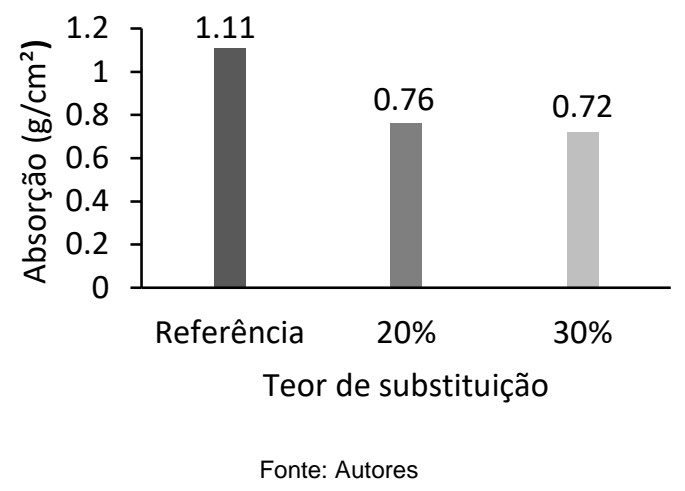

\subsection{Absorção por Imersão}

De acordo com a Tabela 6, no ensaio de absorção de água por imersão constou-se que as amostras com $20 \%$ de teor de substituição tiveram um acréscimo de 10,59\% na taxa de absorção em relação ao concreto de referência. Já as amostras produzidas com 30\% de agregados reciclados tiveram um acréscimo de $3,46 \%$ na taxa de absorção em relação ao concreto de referência.

Tabela 6: Resultados do ensaio de absorção por imersão

\begin{tabular}{ccccc}
\hline \multirow{2}{*}{$\begin{array}{c}\text { Teor } \\
\text { de } \\
\text { subst. }\end{array}$} & \multicolumn{3}{c}{$\begin{array}{c}\text { Absorção de água por imersão } \\
\text { (\%) }\end{array}$} & $\begin{array}{c}\text { Índice } \\
\text { de } \\
\text { vazios } \\
\text { (\%) }\end{array}$ \\
\hline Ref. & 4,91 & 0,1 & 2,03 & 10,74 \\
\hline $20 \%$ & 5,43 & 0,27 & 4,97 & 12,97 \\
\hline $30 \%$ & 5,08 & 0,2 & 3,94 & 12,27 \\
padrão & $\begin{array}{c}\text { Coef. de } \\
\text { variação }\end{array}$ & \\
\hline \multicolumn{5}{c}{ Fonte: Autores } \\
\end{tabular}

A Figura 5 mostra a influência do teor do RAP sobre a absorção por imersão, a partir de análise estatística.

Figura 5: Resultados ensaio absorção por imersão.

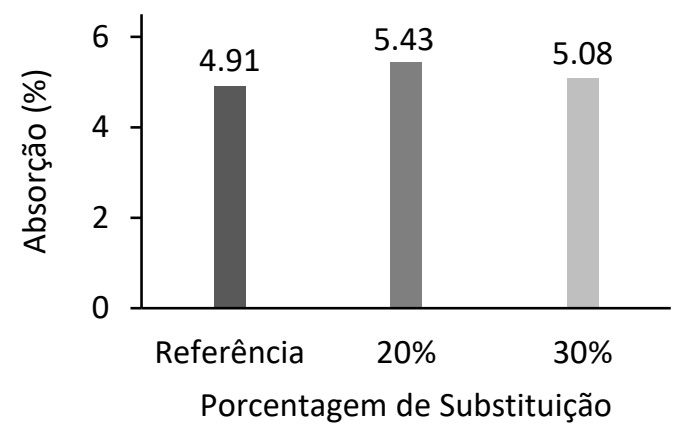

Fonte: Autores 


\subsection{Análise Estatística}

A resistência à compressão axial, absorção de água por imersão e absorção de água por capilaridade foram analisadas por análise de variância (ANOVA). A ANOVA verifica o grau de diferença entre os concretos estudados sobre a variável resposta considerando sua distribuição próxima da normal. $\mathrm{A}$ tabela 7 demostra a contribuição do teor de RAP sobre as variáveis respostas com um nível de confiança de $95,0 \%$. O valor $P$ testa a significância estatística de cada um dos fatores, quando o mesmo é inferior a 0,05 o fator tem um efeito estatisticamente significativo sobre a propriedade estudada.

Tabela 7: Resultado de análise de variância -valor $\mathrm{P}$ e significância - das variáveis sobre as propriedades estudadas

\begin{tabular}{llll}
\hline Variável & $\begin{array}{l}\text { Resist. à } \\
\text { compressão } \\
\text { axial }\end{array}$ & $\begin{array}{l}\text { Absorção } \\
\text { de água }\end{array}$ & $\begin{array}{l}\text { Absorção } \\
\text { capilar }\end{array}$ \\
\hline \%RAP & $0,004728^{*}$ & $0,036878^{*}$ & $0,000605^{*}$ \\
\hline \multicolumn{4}{r}{ *Significativo } \\
\end{tabular}

\section{Considerações Finais}

Nos ensaios de resistência à compressão axial, foi verificado que o aumento da substituição do agregado graúdo natural pelo agregado graúdo reciclado do RAP, resultou em uma diminuição nas resistências. No entanto, mesmo possuindo uma queda nos valores obtidos na resistência à compressão axial, todos os concretos obtiveram resistência acima de $20 \mathrm{Mpa}$, sendo seu uso viável como concreto estrutural de acordo com a NBR 6118 (ABNT, 2014).

$\mathrm{Na}$ absorção por capilaridade todos os concretos com substituição do agregado graúdo natural pelo agregado graúdo do RAP obtiveram absorção inferior ao concreto de referência, sendo vantajoso seu emprego em concretos estruturais. Pode-se verificar que na absorção por imersão todos os concretos com substituição do agregado graúdo natural pelo agregado graúdo do RAP obtiveram absorção superior à argamassa referência.

Através dos resultados mecânicos encontrados, foi possível concluir que, embora a substituição do agregado graúdo natural por RAP nos concretos estruturais diminua a sua resistência a compressão e o seu abatimento, quando comparado ao concreto sem substituição. Todavia mantem valores de resistência que possibilitam o seu uso como concreto estrutural. Os resultados do estudo demonstram que a substituição parcial do agregado graúdo natural por RAP é satisfatoriamente viável.

\section{Referência}

AL-MUFTI, R.L.; FRIED, A.N. Improving the strength properties of recycled asphalt aggregate concrete, Construction and Building Materials, v.149, p.45-52, 2017.

ASSOCIAÇÃO BRASILEIRA DE NORMAS TÉCNICAS - NBR 5738: 2003. Concreto: procedimento para moldagem e cura de corpos-de-prova. Rio de Janeiro, 2003.

ASSOCIAÇÃO BRASILEIRA DE NORMAS TÉCNICAS - NBR 5739: 2007. Concreto: ensaios de compressão de corpos-de-prova cilíndricos. Rio de Janeiro, 2007.

ASSOCIAÇÃO BRASILEIRA DE NORMAS TÉCNICAS - NBR 6118: 2014. Projeto de estruturas de concreto - Procedimento. Rio de Janeiro, 2014.

ASSOCIAÇÃO BRASILEIRA DE NORMAS TÉCNICAS - NBR 9778: 2009. Argamassa e concreto endurecidos - Determinação da absorção de água, índice de vazios e massa específica. Rio de Janeiro, 2009.

ASSOCIAÇÃO BRASILEIRA DE NORMAS TÉCNICAS - NBR 9779: 2013. Argamassa e concreto 
endurecidos - Determinação da absorção de água por capilaridade. Rio de Janeiro, 2013.

ASSOCIAÇÃO BRASILEIRA DE NORMAS TÉCNICAS - NBR NM45: 2006. Agregados: determinação da massa unitária e do volume de vazios. Rio de Janeiro, 2006.

ATOYEBI, O.D.; SADIQ, O.M. Experimental data on flexural strength of reinforced concrete elements with waste glass particles as partial replacement for fine aggregate, Data in Brief, v.18, p.846-859, 2018.

BEZERRA, I. M. T. Cinza da casca do arroz utilizada em argamassas de assentamento e revestimento. 2010. Dissertação de mestrado - Universidade Federal de Campina Grande, Campina Grande, 2010.

BOUSSETTA, I.; KHAY, S.E.E.; NEJI; J., Experimental testing and modelling of roller compacted concrete incorporating RAP waste as aggregates. European Journal of Environmental and Civil Engineering, 2018.

CONFEDERAÇÃO NACIONAL DO TRANSPORTE - CNT. Anuário CNT do transporte: Estatística consolidada. 2017. Disponível em: Acesso em: 20 dezembro de 2017.

ERDEM, S., BLANKSON, M.A., Environmental performance and mechanical analysis of concrete containing recycled asphalt pavement (RAP) and waste precast concrete as aggregate, Journal of Hazardous Materials, v.264, p.403-410, 2014.

ESTEVES, M. R. Estudo do potencial energético e aproveitamento das cascas de coco verde para a produção de briquete em Maceió-AL. 2014. Dissertação de mestrado - Universidade Federal de Alagoas, Maceió, 2014.

KAREIN, S.M.M.; RAMEZANIANPOUR, A.A.; EBADI, T.; ISAPOUR, S.; KARAKOUZIAN M., A new approach for application of silica fume in concrete: Wet granulation, Construction and Building Materials, v.157, p.573-58, 2017.

MENEZES, R. R.; NEVES, G. A. e FERREIRA, H. C. O estado da arte sobre o uso de resíduos como matérias-primas cerâmicas alternativas. Revista Brasileira de Engenharia Agrícola e Ambiental, Campina Grande, v.6, n.2, p.303-313,2002.

NEVILLE, A. M. Propriedades do Concreto. Porto Alegre: Bookman Editora, 2015.

O’ REILLY, V.D. Método de dosagem de concreto de elevado desempenho. Pini, São Paulo,1992.

SACHET, T.; BALBO, J.T.; F.T. BONSEMBIANTE. Interpretação da perda de resistência em concretos secos com incorporação de fresados asfálticos com apoio de análise microscópica. Revista IBRACON de Estruturas e Materiais, v.6, n.6, p. 933-954, 2013.

SILVA, R. B.; ANGULO, S. C.; PILEGGI, R. G.; SILVA, C. O. Concretos secos produzidos com agregados reciclados de RCD separados por densidade. Ambiente Construído, Porto Alegre, V.15, n. 4, p. 335-349, 2015. 